\title{
RANCANG BANGUN SISTEM INFORMASI BENGKEL UNTUK PENGELOLAAN TRANSAKSI DAN PENINGKATAN PELAYANAN KEPADA PELANGGAN
}

\author{
Rin Rin Meilani Salim \\ Dosen STMIK Mikroskil \\ Jalan Thamrin No.140 Medan \\ Sur-el : rinrin.meilani@mikroskil.ac.id
}

\begin{abstract}
Bengkel is a business entity engaged in the sales and service of vehicle repair. The business process in the bengkel handles activities of purchasing, inventory, sales and service. In handling these activities, several problems were found, including frequent loss of purchase invoices, didn't have debt due reports, inventory of goods not recorded properly, frequent errors in recording and calculating sales and service, not yet well-recorded technicians handling each repair from customers, and there are no purchasing reports to know purchase target achievement. Therefore, the bengkel needs an information system to manage daily transactions. The use of bengkel information systems will certainly improve service to customers because all activities and transactions are well managed by the bengkel information system. The information system developed has the advantage of being able to customize features according to needs and is flexible to be used by all bengkel.
\end{abstract}

Keywords: Bengkel Information System, Bengkel, Purchasing, Inventory, Sales, Service

\begin{abstract}
Abstrak : Bengkel merupakan suatu badan usaha yang bergerak di bidang penjualan dan pelayanan perbaikan kendaraan. Proses bisnis pada bengkel menangani kegiatan pembelian, persediaan, penjualan dan service. Dalam menangani kegiatan tersebut ditemukan beberapa kendala, diantaranya sering terjadi kehilangan faktur pembelian, belum adanya laporan hutang jatuh tempo, stok barang tidak terdata dengan baik, sering terjadi kesalahan dalam mencatat dan menghitung penjualan dan service, belum tercatat dengan baik teknisi yang menangani setiap perbaikan dari pelanggan, dan belum adanya laporan pembelian untuk mengetahui pencapaian target pembelian. Oleh karena itu, bengkel membutuhkan sistem informasi untuk mengelola transaksi sehari-hari. Dari pemanfaatan sistem informasi bengkel tentunya akan meningkatkan pelayanan kepada pelanggan karena seluruh kegiatan dan transaksi dikelola dengan baik oleh sistem informasi bengkel. Sistem informasi yang dikembangkan ini memiliki keunggulan dimana dapat mengkustomisasi fitur sesuai dengan kebutuhan dan flexibel untuk dapat digunakan semua bengkel.
\end{abstract}

Kata kunci: Sistem Informasi Bengkel, Bengkel, Pembelian, Persediaan, Penjualan, Service

\section{PENDAHULUAN}

Perkembangan teknologi membawa banyak dampak pada usaha bisnis dimana dengan memanfaatkan teknologi perusahaan akan lebih mudah dalam mengelola transaksi, membuat laporan, mengelola persediaan, dan mengurangi kesalahan pencatatan maupun perhitungan. Perusahaan harus melirik pemanfaatan teknologi yaitu sistem informasi untuk bisnisnya. Ketika perusahaan tidak memanfaatkan sistem informasi maka perusahaan akan tertinggal dari perusahaan pesaing dalam manajemen atau pengelolaan transaksi sehari-hari. Perusahaan akan kalah bersaing dan ketinggalan zaman ketika perusahaan tidak mampu mengelola permintaan pelanggan dengan cepat, tepat dan efektif. Oleh karena itu, perusahaan dituntut untuk menggunakan sistem informasi. 
Bengkel adalah suatu badan usaha yang bergerak di bidang penjualan dan pelayanan perbaikan kendaraan. Proses bisnis sebuah bengkel mengelola banyak transaksi mulai dari pembelian, persediaan, penjualan dan service. Penulis mencoba melakukan interview kepada beberapa pemilik bengkel yang masih belum memanfaatkan sistem informasi. Ketika menjalankan proses bisnis ini menggunakan cara manual maka ditemukan beberapa permasalahan. Dalam menjalankan usahanya, bagian pembelian mengalami kendala dimana faktur pembelian sering tidak tersimpan dengan baik ataupun hilang. Di samping itu, pemilik tidak memiliki rekap yang baik terkait laporan hutang jatuh tempo.

Selain itu, pada bagian persediaan tidak mengetahui dengan pasti stok barang yang tersedia karena pencatatan manual tidak mendukung stok yang up-to-date sehingga hal ini dapat menyebabkan bagian pembelian melakukan pembelian terhadap barang yang sudah ada ataupun bagian pembelian belum melakukan pembelian terhadap barang yang sudah mencapai stok minimum.

Kendala lainnya ditemukan pada bagian penjualan dan service, dimana sering terjadi kesalahan dalam mencatat dan menghitung penjualan barang dan jasa service kepada pelanggan. Hal ini tentunya dapat merugikan salah satu pihak, baik itu pelanggan ataupun bengkel. Kemudian ketika ada keluhan atau komplain dari pelanggan terkait barang maupun jasa yang sudah diberikan, pihak bengkel kesulitan mengetahui teknisi yang sebelumnya melakukan perbaikan. Selain itu, biasanya bengkel mendapatkan tawaran dari pemasok, jika bengkel mampu menjual barang pemasok sesuai target yang diberikan maka bengkel akan mendapatkan hadiah. Terkait hal ini, bengkel kesulitan mendata dan mengetahui sudah capai berapa target pembelian yang dilakukan karena tidak adanya pendataan dan laporan yang dibuat.

Oleh karena itu, kegiatan transaksi di bengkel sudah sewajarnya dikelola menggunakan sistem informasi. Sistem Informasi Bengkel akan mampu mendukung transaksi pembelian, sistem informasi akan mampu mendata setiap pemesanan pembelian, penerimaan barang, penerimaan faktur pembelian, pembayaran hutang dan mengingatkan pembeli terkait hutang yang akan jatuh tempo. Melalui sistem informasi, bengkel dapat mendata dengan baik stok barang yang tersedia di gudang dan mengetahui dengan pasti barang-barang apa saja yang perlu dilakukan pemesanan pembelian dan mendata dengan baik barang apa saja yang rusak ataupun hilang.

Melalui pemanfaatan sistem informasi, seluruh kegiatan penjualan barang ataupun pengambilan barang untuk kegiatan service dan service kendaraan pelanggan akan dicatat dan dihitung oleh sistem sehingga kesalahan akan diminimalisir. Sistem informasi bengkel juga dapat mencatat teknisi yang menangani penjualan dan service sehingga jika ada keluhan atau komplain dari pelanggan, teknisi sebelumnya dapat bertanggung jawab menangani keluhan tersebut. Sistem informasi bengkel akan mampu menghasilkan laporan pembelian dari pemasok untuk mengetahui capaian target bengkel agar mendapatkan hadiah dari pemasok. 
Sistem Informasi Bengkel yang dikembangkan ini bukan yang pertama dikembangkan, sudah banyak sistem informasi serupa. Akan tetapi, pada sistem informasi ini penulis menawarkan keunggulan sistem informasi bengkel yang lengkap untuk seluruh kegiatan pembelian, persediaan, penjualan dan service yang dapat dikustomisasi fiturnya agar dapat disesuaikan dengan kebutuhan setiap bengkel. Selain itu, Besar atau kecilnya suatu bengkel maupun bengkel yang melayani perbaikan sepeda motor dan mobil dapat menggunakan sistem informasi bengkel yang dikembangkan penulis sehingga sistem ini dikembangkan penulis se-flexibel mungkin agar dapat digunakan oleh seluruh bengkel.

Dengan memanfaatkan sistem informasi bengkel, tentunya akan membuat pelanggan menjadi puas dengan pelayanan yang cepat dan informasi yang dihasilkan akurat, tepat waktu dan relevan [1] terutama dalam mencatat transaksi dan mencetak faktur. Barang-barang untuk persediaan di bengkel juga terkelola dengan baik sehingga senantiasa stok tersedia untuk pelanggan yang akan meningkatkan kepuasan pelanggan.

\section{METODOLOGI PENELITIAN}

Metodologi penelitian yang digunakan dalam pengembangan sistem informasi bengkel ini adalah Siklus Hidup Pengembangan Sistem (SHPS) atau Systems Development Life Cycle (SDLC) dimana dari 7 tahapan yang ada pada SHPS, penulis melakukan penelitian ini hingga tahapan 5. Kelima tahap tersebut adalah: [2] [3]

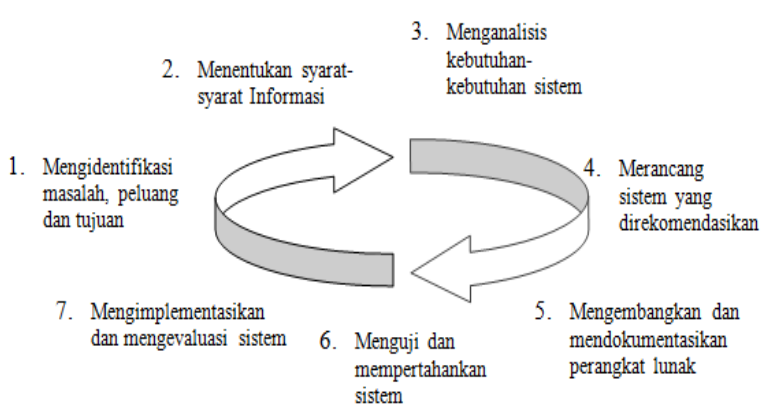

Gambar 1. Tahapan Metodologi SHPS

1. Mengidentifikasi masalah, peluang dan tujuan Penulis mencoba melakukan wawancara kepada beberapa pemilik bengkel yang ada di kota Medan, rumusan masalah yang didapatkan adalah sebagai berikut:

a. Faktur pembelian sering tidak tersimpan dengan baik dan sulit untuk mengetahui hutang jatuh tempo

b. Stok barang tidak terdata dengan baik sehingga ada barang yang menumpuk dan ada yang mencapai stok minimum bahkan habis

c. Sering terjadi kesalahan dalam mencatat dan menghitung penjualan dan service, dan belum tercatat teknisi yang menangani service

d. Belum adanya laporan pembelian untuk mendukung bengkel mencapai target pembelian dan mendapatkan hadiah dari pemasok

Rumusan masalah diatas dapat digambarkan ke dalam fishbone [4]. Penulis yakin adanya peluang dengan pemanfaatan sistem informasi bengkel untuk mencapai tujuan yang diharapkan.

2. Menentukan syarat-syarat informasi

Pada tahap ini, penulis mencoba mengkaji dan mengamati kegiatan-kegiatan yang dijalankan 
pada bengkel. Penulis juga melakukan observasi pada beberapa aplikasi atau sistem informasi best practice dan membaca buku panduannya, seperti accurate [5] [6], dan SAP Fundamental [7] serta proses bisnis penjualan [8], pembelian [9], dan persediaan [10] di software SAP. Kemudian penulis mencoba menentukan ruang lingkup yang akan dibahas.

a. Input yang dibahas meliputi data pengguna, data kustomisasi fitur, data pemasok, data pelanggan, data tipe kendaraan, data merk barang, data barang, data teknisi, data pesanan pembelian, data penerimaan barang, data penerimaan faktur pembelian, data pembayaran hutang, data retur pembelian, penyesuaian persediaan, data service, data penjualan barang dan jasa, data pembayaran penjualan dan jasa, data komplain dan data retur penjualan.

b. Proses yang dibahas meliputi proses pembelian, persediaan, penjualan dan service.

c. Output yang dibahas meliputi laporan pemasok, laporan pelanggan, laporan barang, laporan teknisi, laporan pesanan pembelian, laporan penerimaan barang, laporan pembayaran hutang, laporan hutang jatuh tempo, laporan retur pembelian, laporan penyesuaian barang, laporan penjualan barang dan jasa, laporan pembayaran penjualan dan jasa, laporan service, laporan komplain dan laporan retur penjualan.

3. Menganalisis kebutuhan sistem

Berdasarkan sistem yang diusulkan dengan fitur yang sudah didaftarkan di atas, maka penulis menganalisis kebutuhan sistem dan menggambarkannya dalam DFD sistem usulan.

4. Merancang sistem yang direkomendasikan Pada tahapan ini dilakukan perancangan sistem untuk input dan output menggunakan Microsoft Visual Studio 2012, merancang struktur menu, melakukan normalisasi dan membuat struktur tabel pada Microsoft SQL Server 2012. Struktur tabel tersebut merupakan sistem basis data, yaitu suatu sistem yang digunakan untuk menyimpan dan mengolah data operasional perusahaan sehingga mampu menghasilkan informasi yang optimal untuk pengambilan keputusan. [11]

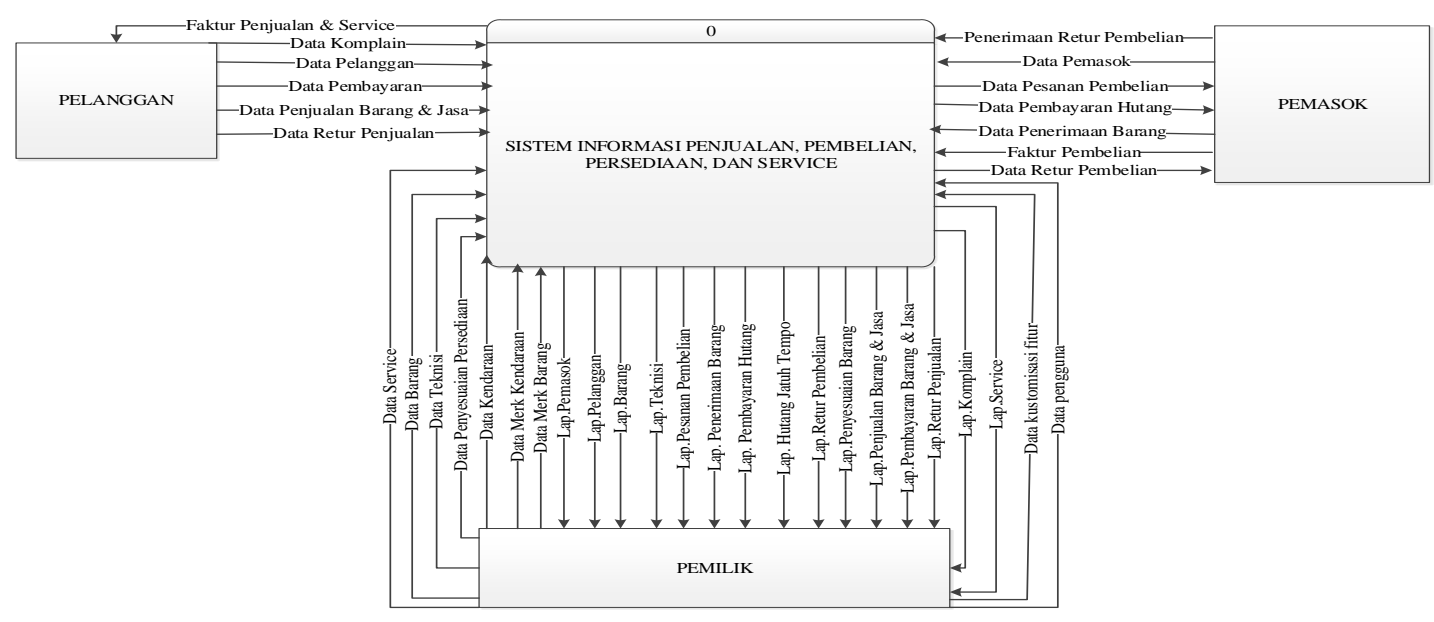

Gambar 2. Diagram Konteks Sistem Usulan 
5. Mengembangkan dan mendokumentasikan sistem

Pada tahap ini, sistem informasi bengkel dikembangkan menggunakan bahasa pemrograman Visual Basic .NET dan database menggunakan Microsoft SQL Server 2012. Sistem informasi bengkel juga didokumentasikan agar dapat dipelajari dan dikembangkan lagi oleh penulis lain kedepannya.

Tahapan 6 yaitu menguji dan mempertahankan sistem, Tahapan 7 yaitu mengimplementasikan dan mengevaluasi sistem belum dilakukan oleh penulis. Sejauh ini penulis hanya sampai tahap mengembangkan apikasi jadi dari sistem informasi bengkel.

\section{HASIL DAN PEMBAHASAN}

Berikut ini adalah beberapa tampilan dari sistem informasi bengkel yang dikembangkan;
Gambar 3 merupakan form kustomisasi fitur yang digunakan oleh pemilik untuk mengatur hak akses setiap pengguna sistem informasi bengkel. Fitur ini digunakan untuk membatasi hak akses masing-masing pengguna. Untuk fitur yang tidak digunakan dan dipakai oleh bengkel, bengkel dapat tidak melakukan centang pada fitur tersebut. Secara garis besar, fitur-fitur yang disediakan adalah fitur yang digunakan oleh bengkel.

Gambar 4 merupakan form data pelanggan digunakan untuk mencatat beserta kendaraan yang dimiliki pelanggan. Tujuan dicatatnya data ini agar setiap kali pelanggan melakukan kunjungan, bengkel tidak perlu mencatat kembali seluruh data pelanggan beserta kendaraannya. Pada data kendaraan pelanggan, disediakan pilihan status kendaraan yaitu milik pelanggan dan sudah terjual, hal ini bertujuan membedakan kendaraan yang pernah di-service tetapi sudah bukan milik pelanggan atau sudah terjual. Jika status kendaraan adalah milik pelanggan maka kendaraan masih milik pelanggan.

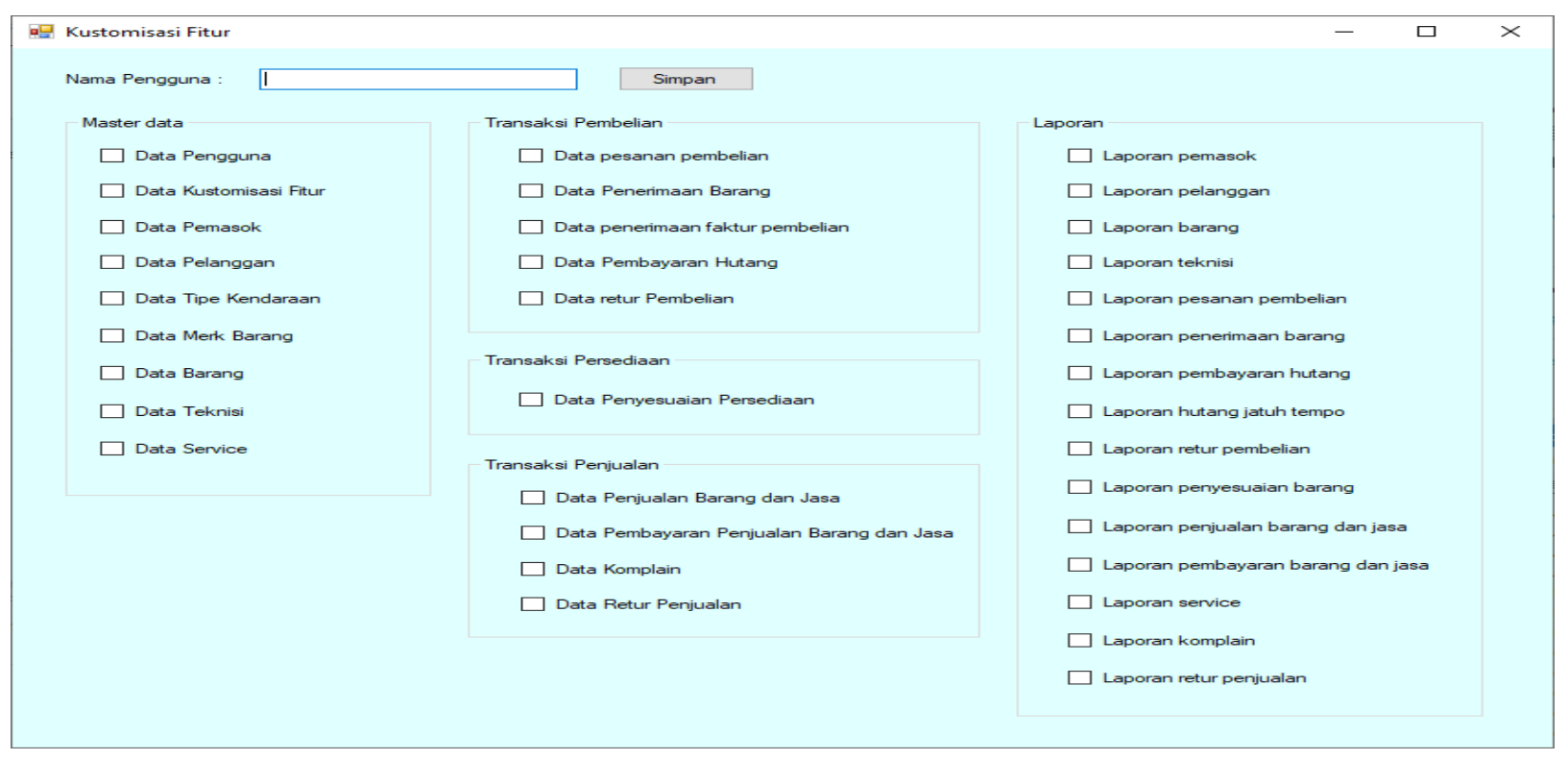

Gambar 3. Kustomisasi Fitur 


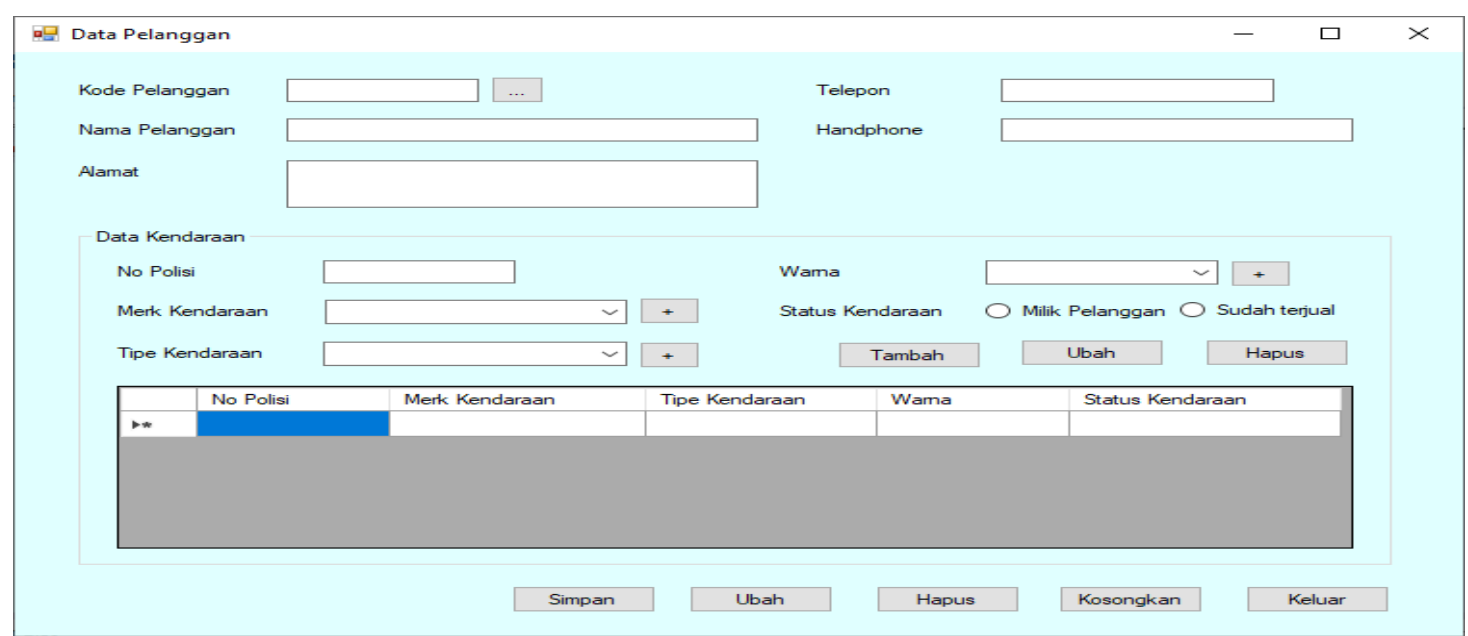

\section{Gambar 4. Data Pelanggan}

Gambar 5 adalah form yang digunakan untuk mencatat setiap pembayaran yang dilakukan oleh bengkel kepada pemasok. Pada form ini disediakan juga pencatatan denda jika bengkel dikenakan denda oleh pemasok. Satu kali pencatatan pembayaran hutang untuk satu pemasok yang sama, mampu menampung lebih dari satu faktur pembelian.

Gambar 6 adalah form yang digunakan untuk mencatat transaksi penjualan dan service di bengkel. Jika pelanggan hanya melakukan service maka pihak bengkel cukup meng-input data service yang dilakukan pelanggan. Jika pelanggan hanya melakukan pembelian barang maka pihak bengkel cukup meng-input data penjualan barang. Jika pelanggan melakukan service dan ada sparepart yang harus diganti sehingga pelanggan perlu memesan barang maka pihak bengkel dapat menginput data service dan penjualan barang. Pada bagian service di form ini mencatat data teknisi yang menangani service.

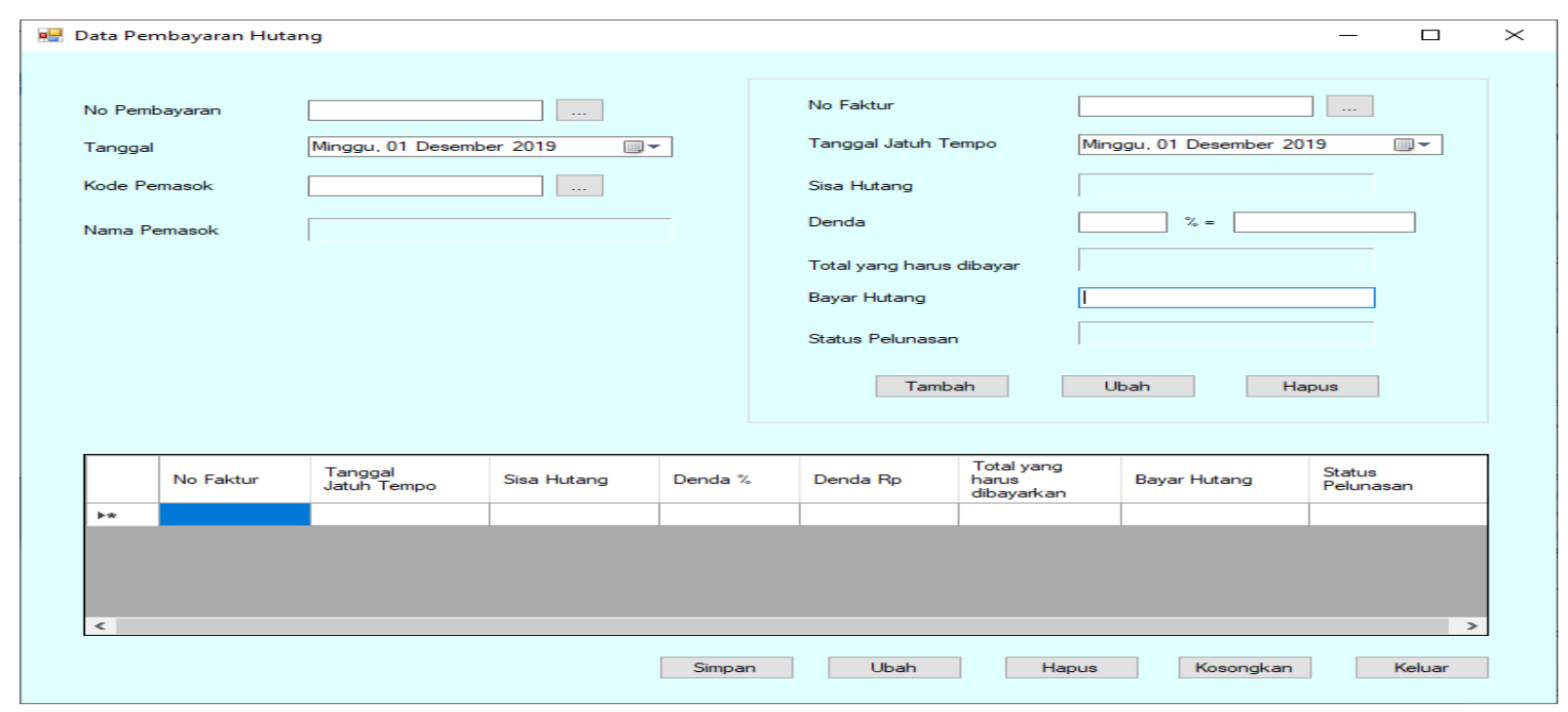

Gambar 5. Data pembayaran hutang 


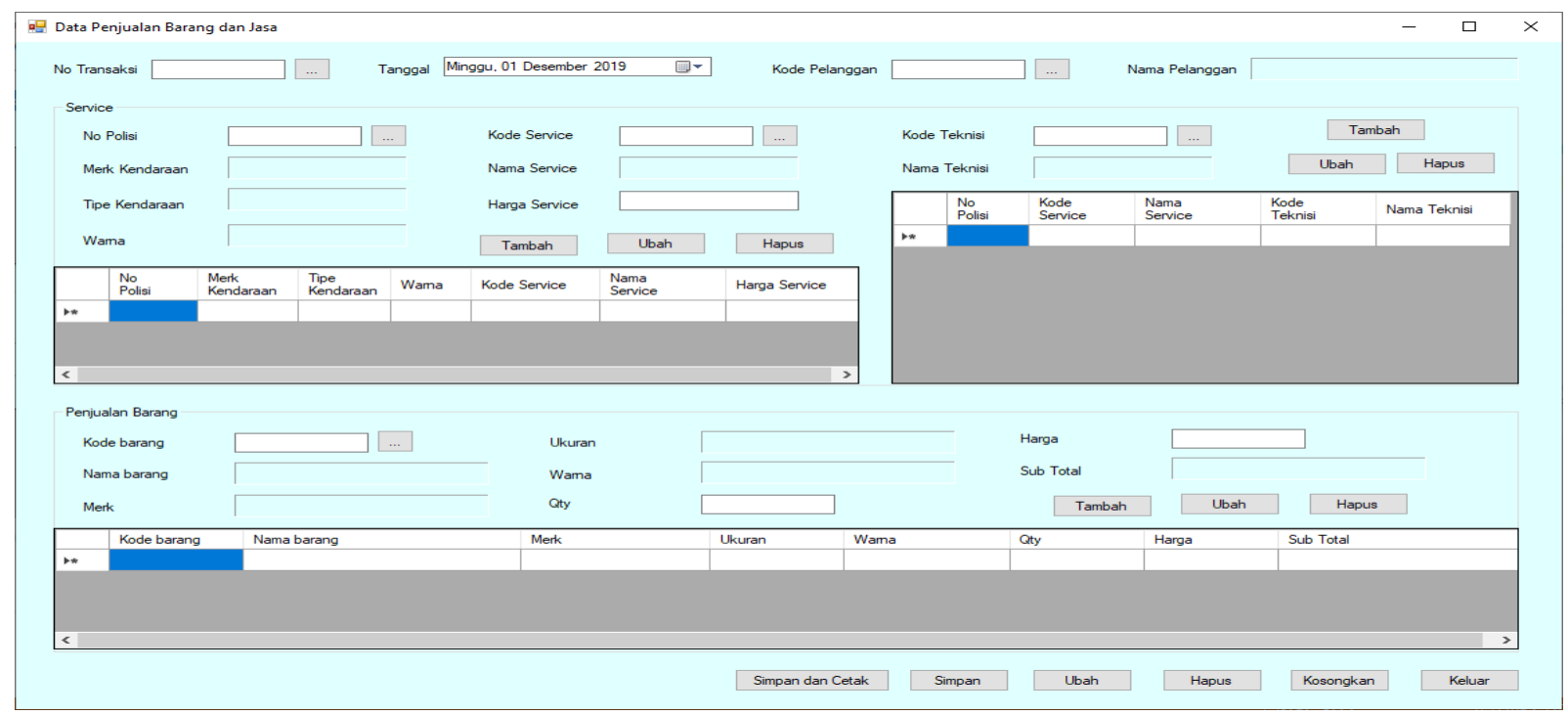

Gambar 6. Data penjualan barang dan jasa

Gambar 7 adalah Form yang digunakan oleh kasir bengkel untuk menerima pembayaran atas pesanan barang ataupun jasa dari pelanggan. Form ini merupakan form yang digunakan sebagai kelanjutan transaksi dari data penjualan barang dan jasa.

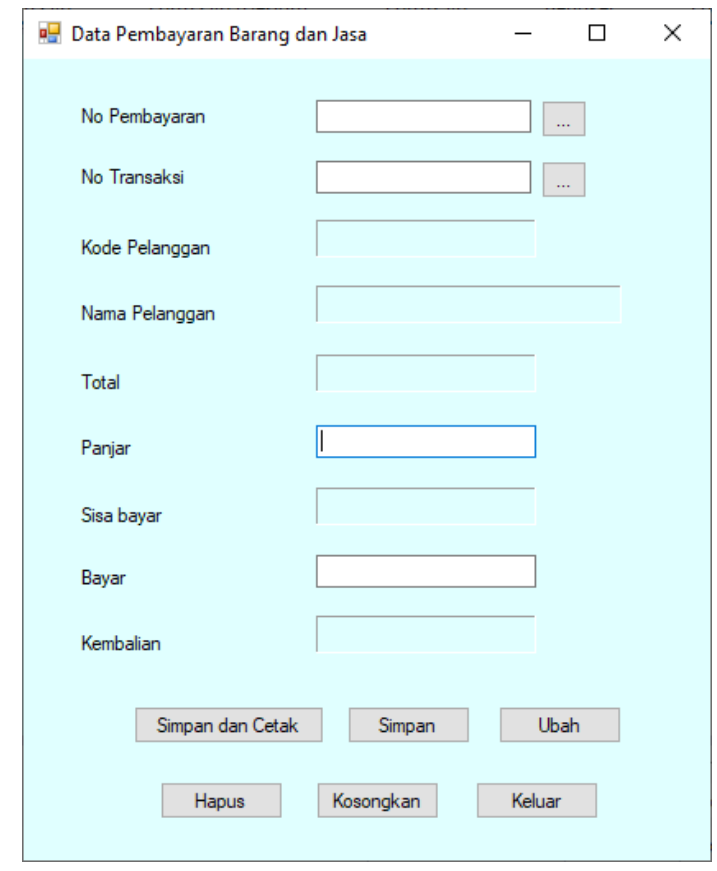

Gambar 7. Data pembayaran barang dan jasa

Gambar 8 adalah Form yang digunakan oleh pihak gudang jika diperlukan penyesuaian persediaan barang. Penyesuaian terjadi karena adanya selisih antara kuantitas barang di komputer dengan kuantitas barang di gudang. Barang disesuaikan bisa dikarenakan ada kerusakan, barang hilang, stok berlebih, ataupun stok berkurang.

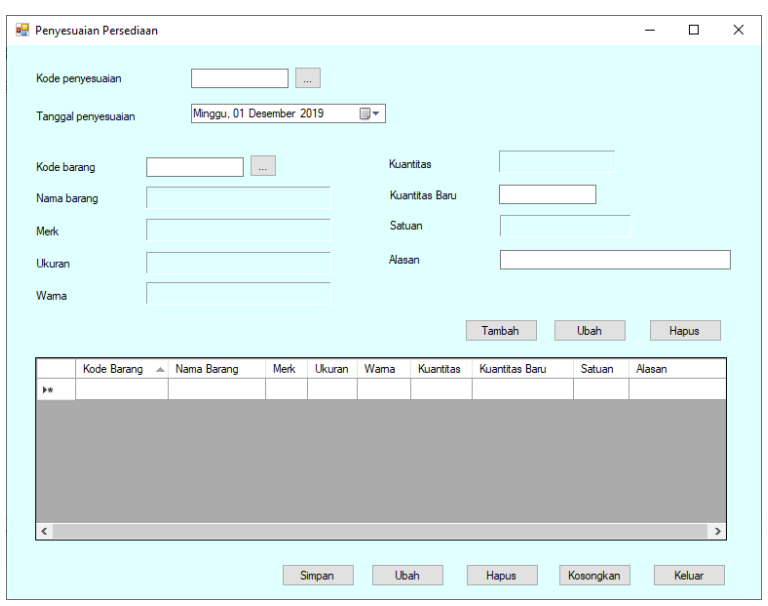

Gambar 8. Penyesuaian persediaan

\section{KESIMPULAN}

Berdasarkan uraian di atas, maka dapat disimpulkan:

1. Sistem Informasi Bengkel dapat dikustomisasi pada fitur dan dibatasi per hak akses pengguna sehingga dapat disesuaikan dengan kebutuhan bengkel.

2. Dengan pemanfaatan sistem informasi 
Bengkel dapat membantu bengkel dalam mengelola transaksi sehari-hari, seperti kegiatan pembelian, persediaan, penjualan dan service. Resiko kehilangan faktur pembelian, lupa masa hutang jatuh tempo, tidak mengetahui dengan pasti stok produk, kesalahan pencatatan dan perhitungan penjualan dan service, dan jumlah pembelian untuk pencapaian target dapat dikelola sistem informasi bengkel.

3. Penggunaan sistem informasi bengkel akan meningkatkan pelayanan kepada pelanggan dengan pelayanan yang lebih cepat, tepat dan akurat serta informasi-informasi yang diberikan lebih up-to-date.

Namun, sistem informasi bengkel ini tidak luput dari kelemahan dimana sistem ini belum mampu menampilkan laporan pendapatan, perhitungan honor teknisi, perhitungan komisi kepada bagian penjualan, dan perhitungan PPN. Fitur tersebut dapat dikembangkan lagi kedepannya oleh penulis lain. Di samping itu, kedepannya sistem informasi bengkel juga dapat dikembangkan berbasis web dengan penambahan fitur booking service online untuk meningkatkan kepuasan pelanggan.

\section{DAFTAR PUSTAKA}

[1] Sutabri. T., Analisa Sistem Informasi, Yogyakarta: Penerbit Andi, 2003.

[2] Kendall, K. E., Kendall, J. E., Analisis dan Perancangan Sistem, Jilid 1 Edisi Kelima, Jakarta: Penerbit Indeks, 2010.

[3] Kendall, K. E., Kendall, J. E., Analisis dan Perancangan Sistem, Jilid 2 Edisi Kelima, Jakarta: Penerbit Indeks, 2010.

[4] Whitten, J. L., Bentley, L.D., Ditmann, K.C., Metode Desain \& Analisis Sistem,
Edisi ke-6, Yogyakarta: Penerbit Andi, 2004.

[5] Perdiasari, L., Latihan Accurate dalam 240 menit, Bisnis 2030 Internet Business Provider. 2009.

[6] Perdiasari, L., Advanced Setup Using Accurate, Bisnis 2030 Internet Business Provider. 2009.

[7] SAP, SAP01 - SAP Fundamental, SAP AG. 2006.

[8] SAP, SCM600 - Business Processes in Sales Order, SAP AG. 2006.

[9] SAP, SCM500 - Business Processes in Procurement, SAP AG. 2006.

[10] SAP, SCM510 - Inventory Management and Physical Inventory, SAP AG. 2006.

[11] Marlinda, L., Sistem Basis Data, Yogyakarta: Penerbit Andi, 2004. 